Article

\title{
Rumen Inoculum Collected from Cows at Slaughter or from a Continuous Fermenter and Preserved in Warm, Refrigerated, Chilled or Freeze-Dried Environments for In Vitro Tests
}

\author{
Mauro Spanghero ${ }^{1, *}$, Maria Chiaravalli ${ }^{2}$, Stefania Colombini ${ }^{2}{ }^{\mathbb{D}}$, Carla Fabro ${ }^{1} \mathbb{( D}$, \\ Federico Froldi $^{3}$, Federico Mason ${ }^{4}{ }^{\circledR}$, Maurizio Moschini ${ }^{3}$, Chiara Sarnataro ${ }^{1}{ }^{(D}$, \\ Stefano Schiavon ${ }^{5}\left(\right.$ and Franco Tagliapietra ${ }^{5}$ (i) \\ 1 Dipartimento di Scienze Agroalimentari, Ambientali e Animali, University of Udine, 33100 Udine, Italy; \\ carla.fabro@uniud.it (C.F.); sarnataro.chiara@spes.uniud.it (C.S.) \\ 2 Dipartimento di Scienze Agrarie e Ambientali, University of Milan, 20122 Milano, Italy; \\ maria.chiaravalli@unimi.it (M.C.); stefania.colombini@unimi.it (S.C.) \\ 3 Dipartimento di Scienze Animali, della Nutrizione e degli Alimenti, Università Cattolica del Sacro Cuore of \\ Piacenza, 29122 Piacenza, Italy; federico.froldi@unicatt.it (F.F.); maurizio.moschini@unicatt.it (M.M.) \\ 4 Department of Biodiversity Protection, Institute of Animal Reproduction and Food Research of Polish \\ Academy of Sciences (IARFR PAS), 10-748 Olsztyn, Poland; f.mason@pan.olsztyn.pl \\ 5 Dipartimento di Agronomia, Animali, Alimenti, Risorse naturali e Ambiente, University of Padova, \\ 35122 Padova, Italy; stefano.schiavon@unipd.it (S.S.); franco.tagliapietra@unipd.it (F.T.) \\ * Correspondence: mauro.spanghero@uniud.it; Tel.: +39-432-558193 or +39-432-558199
}

Received: 7 September 2019; Accepted: 8 October 2019; Published: 16 October 2019

Simple Summary: The utilization of animal donors of rumen fluid for laboratory experiments can raise ethical concerns due to invasive methods of collection (rumen cannulated or intubated animals). Societies are strongly oriented to support cruelty free experiments and alternatives to the collection of rumen fluids from live animals are urgently requested from the scientific community. Thus, in order to attenuate the dependence of laboratories on animal donors, this study compared the rumen inoculum collected at slaughter with the fermentation liquid from a rumen continuous fermenter and both rumen inoculum were used fresh or preserved (by refrigeration, chilling and freeze-drying). The results support the possibility of using continuous fermenters to generate inoculum for in vitro purposes, and short-term refrigeration is confirmed to be a valuable storage system to facilitate transfer inoculum from the collection sites. These findings should attenuate the need for laboratories' frequent collections from animals while continuing research in ruminant nutrition.

\begin{abstract}
The utilization of animal donors of rumen fluid for laboratory experiments can raise ethical concerns, and alternatives to the collection of rumen fluids from live animals are urgently requested. The aim of this study was to compare the fresh rumen fluid (collected at slaughter, $\mathrm{W}$ ) with that obtained from a continuous fermenter (RCF) and three methods of rumen fluid preservation (refrigeration, R, chilling, C, and freeze-drying, FD). The fermentability of different inoculum was evaluated by three in vitro tests (neutral detergent fiber (NDF) and crude protein (CP) degradability and gas production, NDFd, RDP and GP, respectively) using six feeds as substrates. Despite the two types of inoculum differed in terms of metabolites and microbiota concentration, the differences in vitro fermentability between the two liquids were less pronounced than expected $(-15$ and $20 \%$ for NDFd and GP when the liquid of fermenter was used and no differences for RDP). Within each in vitro test, the data obtained from rumen and from fermenter liquids were highly correlated for the six feeds, as well as between $\mathrm{W}$ and $\mathrm{R}(\mathrm{r}: 0.837-0.985 ; p<0.01)$. The low fermentative capacity was found for $\mathrm{C}$ and, particularly, FD for liquids. RCF could be used to generate inoculum for in vitro purposes and short-term refrigeration is a valuable practice to manage inoculum.
\end{abstract}


Keywords: rumen liquid; in vitro fermentation; rumen degradability; gas production

\section{Introduction}

Rumen fluid sampled from live animals is used in laboratory experiments (e.g., in vitro rumen fermentation) to evaluate the nutritive value and gaseous emissions of ruminant feeds [1,2] or to inoculate continuous fermenters for studies of rumen fermentation [3].

In general, the utilization of animals as donors of rumen fluid can raise some ethical concerns, because the collection of rumen fluid is an invasive practice, which requires donor animals that are surgically modified (e.g., rumen cannulated), or immobilised and intubated with esophageal probes. An alternative is to collect rumen fluid from animals slaughtered for production purposes in commercial slaughterhouses, but it is difficult to monitor feeding before slaughter. Overall, societies are strongly oriented to support cruelty free experiments and alternatives to collection of rumen fluids from live animals are urgently requested of the scientific community to continue research activity in ruminant nutrition.

Rumen continuous fermenters (RCFs) are laboratory apparatus developed to simulate the rumen conditions for studies of rumen metabolism. They generate a fermenting fluid by starting from an initial rumen inoculum and by a continuous influx of artificial saliva, an output of fermentation products and a constant supply of nutrients (substrates). However, they could also be modified and adapted to be used as artificial generators of rumen fermentation fluid, which could be standardised with respect to several conditions (type and amount of fermentable substrate, $\mathrm{pH}$, dilution, etc.). There are studies which have compared fermentation liquids from different RCFs or between fluids collected from rumens and fermenters [3-7]. The liquid from fermenters is less concentrated in terms of volatile fatty acids (VFA) and protozoa, and the cellulosolitic bacterial strains seem reduced in some types of RCF (e.g., Rusitec, [8]) while in other fermenters, the bacteria microbiota was comparable to that measured directly on the rumen inoculum collected in vivo [6,7]. However, no experiments have simultaneously compared rumen and RCFs fluids as inoculum in terms of results of different in vitro tests.

Overall, independently from the mode of inoculum provision, the possibility of preserving rumen fluid and to create stocks would allow the concentration of the collection in specialized centers to facilitate the transfer of the inoculum and reduce the need of laboratories to frequently collect liquids from live animals. The preservation techniques of rumen fluid have been investigated in several studies, which have mainly considered the usage of low temperatures (e.g., refrigeration and chilling at -20 , at $-80^{\circ} \mathrm{C}$, or in liquid $\mathrm{N}$ ), the addition of cryoprotectants, and also freeze-drying [9-13]. In general, there are encouraging findings, but also a scarce homogeneity among trials in terms of measurement of the maintenance of the fermentative capacity of liquid after preservation.

The present research has the general aim to attenuate the needs of direct collection of rumen fluid from animals by: (i) artificially generating rumen fermenting fluids; (ii) evaluating preservation methods for stock rumen fluid. These technologies should reduce the need for laboratories to frequently collect from animals, with the potential advantage of reducing inoculum variability. The specific aim is to compare the fresh rumen fluid (collected at slaughter) with that obtained from a stratified single-flow RCF system [14] and three methods of rumen fermenting fluid preservation (refrigeration, chilling and freeze-drying).

Unlike other research, the novelty of this study is to compare the different inoculum in terms of the results obtained by three widely utilised in vitro methods (degradability of neutral detergent fiber, NDFd, degradability of protein (RDP), and gas production, (GP) respectively). The chosen in vitro tests allow a wide evaluation of the fermentation potential of inoculum, because they quantify the fermentation of main dietary components of ruminant rations, such as fibers (NDFd), protein (RDP) and (mainly) non-fibrous carbohydrates (GP). 


\section{Materials and Methods}

\subsection{Trial Organization}

The experiment was organised in two subsequent identical fermentation trials (runs) and was carried out by four Italian research groups from the University of Milano, Padova, Piacenza, and Udine (Labs 1, 2, 3, and 4, respectively).

For each trial, 4 dry multiparous Holstein Friesian cows were slaughtered for production purposes in a commercial slaughterhouse, after being fed for 3 weeks a basal diet (32.3\% meadow hay, 34.0\% corn silage, $27.3 \%$ compound feed and $6.4 \%$ soybean meal). The cows of both runs were in good health, housed in the same barn located $50 \mathrm{~km}$ from the slaughterhouse, fed the last feeding in the morning $2 \mathrm{~h}$ before being moved to the slaughterhouse, and had free access to fresh water until slaughter. After slaughter, the rumen liquors, collected in equal amounts from the 4 cows by Lab 4 , were coarsely filtered, the liquids bulked together during continuous flushing with $\mathrm{CO}_{2}$, and then divided into 2 main amounts (see Figure 1). The first amount represented the rumen inoculum for the in vitro tests (NDFd, RDP and GP test), while the second amount was used to inoculate the RCF system. Both inoculum were used as: warm at $39{ }^{\circ} \mathrm{C}(\mathrm{W})$, refrigerated at $4{ }^{\circ} \mathrm{C}(\mathrm{R})$, chilled at $-80{ }^{\circ} \mathrm{C}(\mathrm{C})$, and freeze-dried (FD). After the collection at slaughter, $\mathrm{W}$ (kept inside pre-warmed thermic bottles flushed with $\mathrm{CO}_{2}$ ) and $\mathrm{R}$ (kept inside bottles flushed with $\mathrm{CO}_{2}$, immersed in ice water within a portable fridge to quickly lower the temperature to $4^{\circ} \mathrm{C}$ ) were divided in aliquots of 250-300 mL each and immediately delivered to Lab 1, 2, and 3 to start the in vitro tests within $6 \mathrm{~h}$ from slaughter. The amounts to be preserved as C, FD or to be used in the RCF fermenter were immediately brought to Lab 4 (maintained warm at $39^{\circ} \mathrm{C}$ ). Here, the $\mathrm{C}$ or FD, amounts were divided in aliquots of $250-300 \mathrm{~mL}$ each. The $\mathrm{C}$ aliquots were chilled at $-80^{\circ} \mathrm{C}$, while the FD aliquots were processed according to Luchini et al. [15]. Briefly, after centrifugation at $5000 \mathrm{~g}$ for $30 \mathrm{~min}$ at $4{ }^{\circ} \mathrm{C}$, the supernatant was discarded, and the residue obtained was chilled at $-80{ }^{\circ} \mathrm{C}$, and subsequently freeze-dried. The $\mathrm{C}$ and FD aliquots were delivered to Lab $1,2,3$ after $30 \mathrm{~d}$ of conservation. Before being used as inoculum, the $\mathrm{C}$ liquids were thawed in a bain-marie at $39{ }^{\circ} \mathrm{C}$ within $2 \mathrm{~h}$ and kept at the same temperature for another $2 \mathrm{~h}$, while the FD liquids were reconstituted to the original volume with the artificial saliva used for the in vitro tests and kept at $39^{\circ} \mathrm{C}$ for $2 \mathrm{~h}$.

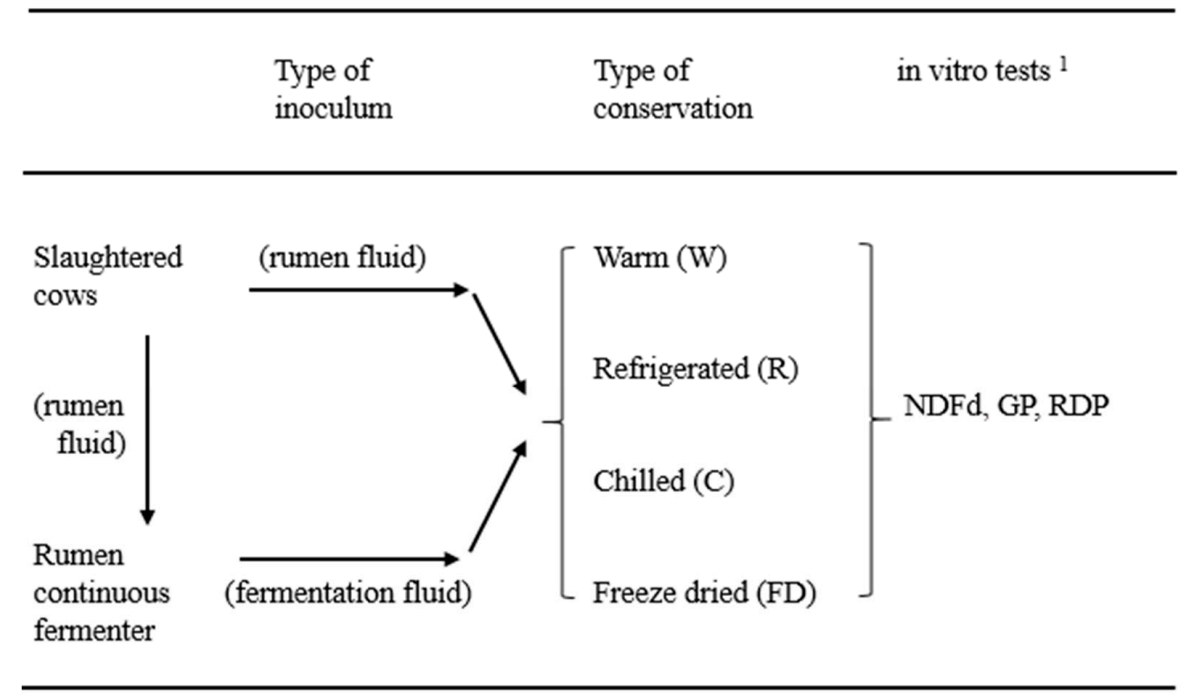

${ }^{1} \mathrm{NDFd}$ : NDF degradability; GP : gas production; RDP : rumen degradable protein.

Figure 1. Schematic representation of the trial organization.

The remaining amount of rumen liquid was immediately used to inoculate the RCF fermenter in Lab 4. On the 9th day of incubation in the RCF, the fermentation fluid was collected, and divided in 
aliquots for each liquid type (W, R, C and FD). The $\mathrm{W}$ and $\mathrm{R}$ aliquots, prepared as previously described for the rumen inoculum, were immediately transferred to Lab 1, 2 and 3 to perform the in vitro tests within $6 \mathrm{~h}$ from the collection of the liquid from the RCF system. The $\mathrm{C}$ and FD aliquots were delivered to Labs 1, 2, and 3 after $30 \mathrm{~d}$ of conservation.

As incubations of liquids $C$ and FD were delayed by $30 \mathrm{~d}$ with respect to $\mathrm{W}$ and $\mathrm{R}$ and the incubations of liquid from the fermenter were delayed by $9 \mathrm{~d}$ from the incubation of rumen liquids. There were in total 4 incubation sessions within each fermentation run.

\subsection{Preparation of the Substrates for the In Vitro Tests}

All the in vitro tests were performed on the following six ingredients: meadow hay, corn silage, wheat bran, distillers, soybean and barley meal. The samples of corn silage were dried $\left(48 \mathrm{~h}\right.$ at $\left.60^{\circ} \mathrm{C}\right)$ and all feed samples were milled through a $1 \mathrm{~mm}$ sieve and then analysed for chemical composition.

\subsection{The Rumen Continuous Fermenter (RCF) System and the In Vitro Tests}

The RCF system, used in Lab 4, was described in detail by Mason et al. [14]. In brief, the system consists of $8 \times 2 \mathrm{~L}$ glass bottles, immersed in a water bath at $39^{\circ} \mathrm{C}$. A peristaltic pump supplies the buffer solution [16] from a reservoir to the fermenters (dilution rate of $5 \% / \mathrm{h}$ ) and the outflow, located at the bottom of the bottles, allows stratification of the feeding material. The bottles were inoculated with $600 \mathrm{~mL}$ of strained rumen fluid and $800 \mathrm{~mL}$ of artificial saliva, and each bottle received a total of $15 \mathrm{~g} / \mathrm{d}$ of dry matter (DM), in two equal doses, at 09:00-17:00, of the same diet used to feed the donor cows before slaughtering. Each fermentation lasted $9 \mathrm{~d}$ and on the last day, the fermentation fluids of the 8 bottles were collected, pooled, and processed to prepare the different inoculum, as previously described.

In all 3 in vitro tests, the inoculum was strained through 4 layers of cheesecloth into pre-warmed $\left(39^{\circ} \mathrm{C}\right.$ ) flasks with $\mathrm{CO}_{2}$ and mixed with the buffer solutions ([17] for NDFd and GP and Van Soest buffer [18] for RDP, in a 1:2 and 1:4 ratio, respectively).

The NDFd was tested by Lab 1. Each feed sample was weighed $(0.250 \pm 0.005 \mathrm{~g})$ in duplicate in Ankom F57 bags (Ankom Technology, Macedon, NY, USA). The bags were incubated in a pre-warmed $100 \mathrm{~mL}$ Erlenmeyer flask closed by a rubber stopper with a Bunsen valve for gas release and maintained at $39^{\circ} \mathrm{C}$ in a water bath with shaking for $48 \mathrm{~h}$. Each flask was inoculated with $90 \mathrm{~mL}$ of the solution under anaerobic conditions, flushing the flask with $\mathrm{CO}_{2}$. At the end of the incubations, the bags were rinsed with cold water until the water ran clear and then placed for $3 \mathrm{~h}$ in a $105^{\circ} \mathrm{C}$ forced-air oven to dry. Subsequently, the NDF concentration was determined for each bag using the fiber analyser (Ankom Technology, Macedon, NY, USA).

The RDP was tested by Lab 3 according to the rumen step of the Ross method [19]. Briefly, each sample was weighed $(1.000 \pm 0.020 \mathrm{~g})$ into a $120 \mathrm{~mL}$ glass bottle equipped with a cap and placed into a $39^{\circ} \mathrm{C}$ water bath $1 \mathrm{~h}$ before the in vitro fermentation. The neutral detergent residue from corn silage was used for microbial contamination correction of the post fermentation feed residues. Each bottle was inoculated with $100 \mathrm{~mL}$ solution under $\mathrm{CO}_{2}$ flushing, closed with the cap, and incubated for $16 \mathrm{~h}$ at $39^{\circ} \mathrm{C}$ in a shaking water bath. After the incubation, the bottle content was vacuum filtered $(110 \mathrm{~mm}$ diameter Whatman Filter Papers 54) and the residue was analyzed for Kjeldahl nitrogen.

The GP was measured after $24 \mathrm{~h}$ incubation by Lab 2 by using a commercial GP apparatus (Ankom Technology, Macedon, NY, USA; [20]). The system consists of 50 bottles hermetically sealed, equipped with a wireless pressure sensor connected to a computer. Each bottle $(317 \mathrm{~mL})$ was filled with $0.500 \pm 0.010 \mathrm{~g}$ of feed and $75 \mathrm{~mL}$ of fermenting solution, obtaining a headspace volume of 242 $\mathrm{mL}$. The bottles were placed in a ventilated incubator at $39 \pm 0.4{ }^{\circ} \mathrm{C}$ and automatically vented at a fixed pressure $(6.8 \mathrm{kPa})$, to prevent overpressure.

All the tests were performed for each feed substrate and for each inoculum type in duplicate ( 8 inoculum types $\times 6$ feeds in duplicate) and were replicated in a second fermentation run. The between-run determinations were considered as experimental repetitions. To account for the incubation 
session effect, a standard rumen fluid was included in each incubation session by each laboratory. Before conducting the whole experiment, Lab 4 prepared a rumen fluid to be used as the control by other labs. The liquid was collected at slaughter from 4 dairy cows (culled in good health) and delivered to Lab 4 within $30 \mathrm{~min}$ in airtight glass-bottles refluxed with carbon dioxide and maintained at $39^{\circ} \mathrm{C}$. The whole amount was divided in small aliquots $(200 \mathrm{~mL})$, frozen at $-20^{\circ} \mathrm{C}$ and distributed to Lab 1, 2 and 3. The frozen-thawed inoculum (in a bain-marie at $39^{\circ} \mathrm{C}$ within $2 \mathrm{~h}$ and kept at the same temperature for another $2 \mathrm{~h}$ ) were added by each Lab into each incubation run (two incubation bottles added with corn silage as substrate) to detect anomalies between runs.

\subsection{Analysis}

\subsubsection{Inoculum Sample Preparation}

The samples of the two inoculum for each preservation treatment were collected before performing the in vitro tests for the following analyses: $\mathrm{pH}, \mathrm{VFA}, \mathrm{NH}_{3}$, and microbial population. The samples for the VFA analysis were acidified with $\mathrm{H}_{2} \mathrm{SO}_{4} 0.1 \mathrm{~N}$ and stored at $-20{ }^{\circ} \mathrm{C}$ while the samples for $\mathrm{NH}_{3}$ were directly stored at $-20^{\circ} \mathrm{C}$. The samples for bacterial DNA analysis were chilled in liquid nitrogen (N) and stored at $-80^{\circ} \mathrm{C}$.

\subsubsection{Chemical Analysis}

The DM content of the feeds was determined by heating at $105^{\circ} \mathrm{C}$ for $3 \mathrm{~h}(\operatorname{method} 930.15 ;$ [21]), and the ash content was subsequently determined after incineration at $550{ }^{\circ} \mathrm{C}$ for $2 \mathrm{~h}$ (method 942.05; [21]). The neutral and acid detergent fiber (NDF and ADF, respectively) analysis was performed with a fiber analyzer (Ankom Technology, Macedon, NY, USA) following the procedure of Van Soest et al. [18] without correction for residual ash. The ether extract (EE) and the $\mathrm{N}$ contents were respectively determined by the solvent extraction and by the Kjeldahl methods (methods 954.02 and 976.05, [21]).

The $\mathrm{pH}$ and the $\mathrm{NH}_{3}$ content of the inoculum were measured with a glass electrode $\mathrm{pH}$ meter (GLP 22, Crison Instruments, S.A. Barcelona, Spain) and an ammonia electrode (Ammonia Gas Sensing Combination Electrode, CHach Company, Loveland, CO, USA, 2001).

For the VFA analysis, the aliquots of the inoculum were centrifuged at 20,000 $\mathrm{g}$ for $30 \mathrm{~min}$ at $20{ }^{\circ} \mathrm{C}$ and the supernatant was then filtered using polypore $0.45 \mu \mathrm{m}$ filters (Alltech Italia, Milan, Italy). The filtrate was injected into a high-performance liquid chromatography instrument (Perkin-Elmer, Norwalk, CN, USA), set to $220 \mathrm{~nm}$ according to the method described by Martillotti and Puppo [22].

\subsubsection{Microbial Analysis}

Genomic DNA was extracted from about $700 \mu \mathrm{L}$ of inoculum samples using the PowerSoil DNA extraction kit (MoBio Laboratories Inc., Carlsbad, CA, USA) with some modifications as described by Kong et al. [23] (2010). DNA concentration, eluted in $50 \mu \mathrm{L}$, was determined by NanoDrop One (Thermo Fisher Scientific Inc., Wilmington, DE, USA).

The quantitative polymerase chain reaction analysis was performed by CFX96 Real Time System (Bio-Rad Technologies Inc, Hercules, CA, USA) using iQ SYBR Green Supermix (Bio-Rad Technologies Inc, Hercules, CA, USA) mixed with $0.3 \mu \mathrm{L}$ of each forward and reverse primer $(0.3 \mu \mathrm{M}), 8.4 \mu \mathrm{L}$ of sterile water and $1 \mu \mathrm{L}$ of gDNA to obtain a reaction volume of $20 \mu \mathrm{L}$. The amplification program included the denaturation step at $98^{\circ} \mathrm{C}$ for $3 \mathrm{~min}$ followed by 40 cycles at $98^{\circ} \mathrm{C}$ for $15 \mathrm{~s}$, annealing at $60{ }^{\circ} \mathrm{C}$ for $30 \mathrm{~s}$ and elongation at $72{ }^{\circ} \mathrm{C}$ for $30 \mathrm{~s}$.

To determine the specificity of the amplification of each primer, the melting curve was performed. The amplification efficiency was calculated using the formula: $E=10^{(-1 / \text { slope })}-1$. The relative abundance of the target bacterial groups or species was expressed in a proportion of the total bacteria $16 \mathrm{~S}$ rRNA gene and was calculated using the following formula: $2^{-\Delta C T}$. 


\subsubsection{Statistical Analyses}

The data from the in vitro tests (NDFd, RDP and GP, within each test and within each feed substrate) and the chemical and microbial composition of fermentation fluids differing for origin and preservation ( $\mathrm{pH}$ values, VFA and ammonia contents and bacteria abundance) were statistically analysed as a factorial $2 \times 4$ completely randomised block ( 2 fermentation runs as blocks) design:

$$
\mathrm{Y}_{\mathrm{ijk}}=\mu+\alpha_{\mathrm{i}}+\beta_{\mathrm{j}}+\gamma_{\mathrm{k}}+(\beta \gamma)_{\mathrm{jk}}+\varepsilon_{\mathrm{ijk}}
$$

where: $y_{\mathrm{ijk}}$ is the experimental data; $\mu$ is the overall mean; $\alpha_{\mathrm{i}}$ is the random effect (block) of the fermentation run ( $i=1,2) ; \beta_{j}$ is the fixed effect of the type of inoculum $(j=1,2) ; \gamma_{k}$ is the fixed effect of the inoculum preservation method $(\mathrm{k}=1,4)$; and $\varepsilon_{\mathrm{ijk}}$ is the random error.

Within each in vitro test data, the Pearson correlation coefficient (r) was calculated for the 6 feeds tested in 2 runs with fermentation liquids, differing for origin (liquids from fermenter versus liquids from rumen, 12 data points) or for the type of conservation (W versus $R, W$ versus $C$ and $W$ versus FD liquids, 12 data points for each correlation).

For all statistical analyses, the probability significance levels $(p)$ were 0.05 and $0.01(p<0.05$ and $p \leq 0.01$, respectively).

\section{Results}

The chemical composition of feeds used as substrates for the in vitro tests and the characteristics of inocula are reported in Tables 1 and 2, respectively.

Table 1. Chemical composition of feeds used as substrates in the in vitro tests.

\begin{tabular}{ccccccc}
\hline \multirow{2}{*}{ Feeds } & $\mathbf{D M}$ & Ash & $\mathbf{C P}$ & EE & NDF & ADF \\
\cline { 2 - 6 } & \% & \% DM & \% DM & \% DM & \% DM & \% DM \\
\hline Corn silage 1 & 91.88 & 4.16 & 7.67 & 3.10 & 36.79 & 20.74 \\
Wheat bran & 89.71 & 5.98 & 16.74 & 3.47 & 47.80 & 13.40 \\
Meadow hay & 95.54 & 11.30 & 7.34 & 1.45 & 58.38 & 34.82 \\
Distillers & 89.15 & 5.87 & 34.32 & 7.79 & 42.87 & 11.86 \\
Soya meal, extr. & 88.88 & 6.95 & 46.09 & 1.19 & 21.11 & 8.88 \\
Barley & 89.79 & 3.08 & 10.65 & 1.55 & 31.89 & 8.30 \\
\hline \multicolumn{7}{c}{ 1 pre-dried samples at $60{ }^{\circ} \mathrm{C}}$.
\end{tabular}

Among the parameters reported in Table 2, the concentration of ammonia and the relative abundance of Fibrobacter succinogenes in fermentation fluids showed a significant interaction $(p<0.05)$ between the origin of the liquid and the preservation method. However, for both parameters the impact of the interaction in terms of contribution to the mean square of the model was much lower than that of the main effects as well the level of significance ( $p<0.05$ vs. $p \leq 0.01$ ). Therefore, this study decided to show and to discuss the main effects of the model.

The liquid from the fermenter had a lower total VFA content, acetic percentage on total VFA, acetic:propionic ratio and ammonia concentration compared with the liquid from rumen (34.9 versus $122.1 \mathrm{mMol}, 57.8$ versus $63.3 \%, 2.9$ versus 5.7 and 15.4 versus $26.1 \mathrm{mg} / \mathrm{dL}$, respectively, $p \leq 0.01$ ). On the contrary, the valeric and isovaleric acid percentages on total VFA were higher in fluid from the fermenter than the rumen liquid ( 1.8 versus $1.1 \%$ and 2.7 versus $1.4 \%$, respectively, $p \leq 0.01)$. The FD preservation differed significantly $(p \leq 0.01)$ from the others for the lowest proportion of acetic, propionic and isovaleric acids and for the very high proportion of isobutyric acid. The FD also had a very low content of ammonia in comparison with $\mathrm{W}$ and $\mathrm{R}(6.4$ versus $21.8-22.3 \mathrm{mg} / \mathrm{dL}, p \leq 0.01$ ), while the $C$ liquid showed the highest concentration $(32.6 \mathrm{mg} / \mathrm{dL}, p \leq 0.01)$. 
Table 2. Volatile fatty acid (VFA) content, $\mathrm{pH}$, ammonia $\left(\mathrm{NH}_{3}\right)$ content and bacteria abundance of fermentation liquids from inoculum differing for origin and for conservation.

\begin{tabular}{|c|c|c|c|c|c|c|c|c|c|c|}
\hline \multirow{2}{*}{ Items } & \multicolumn{2}{|c|}{ Type of Inoculum (TI) } & \multicolumn{4}{|c|}{ Type of Conservation ${ }^{1}$ (TC) } & \multirow{2}{*}{$\mathrm{TI}^{2}$} & \multirow{2}{*}{$\mathrm{TC}^{2}$} & \multirow{2}{*}{$\mathrm{TI} \times \mathrm{TC}^{2}$} & \multirow{2}{*}{ RMSE $^{2}$} \\
\hline & From Rumen & From Fermenter & Warm (W) & Refrigerated (R) & Chilled (C) & Freeze-Dried (FD) & & & & \\
\hline Samples, $n$ & 8 & 8 & 4 & 4 & 4 & 4 & & & & \\
\hline Total VFA (mMol) & 122.1 & 34.9 & 76.4 & 74.1 & 100.3 & 63.4 & ** & ns & ns & 25.98 \\
\hline \multicolumn{11}{|c|}{ VFA composition ( $\%$ of total VFA) } \\
\hline Acetic (A) & 63.3 & 57.8 & $67.3^{\mathrm{A}}$ & $66.0^{\mathrm{A}}$ & $65.7^{\mathrm{A}}$ & $43.4^{\mathrm{B}}$ & * & ** & ns & 3.72 \\
\hline Propionic (P) & 12.5 & 20.2 & $18.2^{\mathrm{A}}$ & $18.5^{\mathrm{A}}$ & $16.9^{\mathrm{A}}$ & $11.9^{\mathrm{B}}$ & $* *$ & ** & ns & 1.84 \\
\hline Isobutyric & 10.9 & 9.6 & $0.4^{\mathrm{B}}$ & $0.4^{\mathrm{B}}$ & $4.2^{\mathrm{B}}$ & $36.0^{\mathrm{A}}$ & ns & $* *$ & ns & 5.77 \\
\hline Butyric & 10.5 & 8.0 & 10.1 & 10.8 & 9.5 & 6.5 & ns & ns & ns & 2.35 \\
\hline Isovaleric & 1.4 & 2.7 & $2.1^{\mathrm{A}}$ & $2.4^{\mathrm{A}}$ & $2.3^{\mathrm{A}}$ & $1.2^{\mathrm{B}}$ & $* *$ & $* *$ & ns & 0.34 \\
\hline Valeric & 1.1 & 1.8 & 1.6 & 1.6 & 1.5 & 1.2 & * & ns & ns & 0.40 \\
\hline$A: P$ & 5.7 & 2.9 & 3.9 & 3.8 & 4.0 & 5.4 & $* *$ & ns & ns & 1.27 \\
\hline $\mathrm{pH}$ & 6.4 & 6.7 & 6.5 & 6.5 & 6.5 & 6.8 & ns & ns & ns & 0.51 \\
\hline $\mathrm{NH}_{3}(\mathrm{mg} / \mathrm{dL})$ & 26.1 & 15.4 & $21.8^{\mathrm{B}}$ & $22.3^{B}$ & $32.6^{\mathrm{A}}$ & $6.4^{\mathrm{C}}$ & $* *$ & $* *$ & $*$ & 3.28 \\
\hline \multicolumn{11}{|c|}{ Relative abundance (\% of total bacteria) } \\
\hline Genus Prevotella & 45.1 & 19.7 & 25.8 & 31.7 & 34.6 & 37.5 & ** & ns & ns & 8.90 \\
\hline Fibrobacter succinogenes & 0.39 & 2.04 & $2.36^{\mathrm{A}}$ & $2.10^{\mathrm{A}}$ & $0.39^{\text {B }}$ & $0.01^{\mathrm{B}}$ & ** & ** & $*$ & 0.63 \\
\hline Ruminococcus albus group & 0.017 & 0.003 & 0.013 & 0.010 & 0.011 & 0.006 & $* *$ & $\mathrm{~ns}$ & $\mathrm{~ns}$ & 0.0056 \\
\hline
\end{tabular}

${ }^{1}$ Means of the type of conservation with different superscripts (A, B, C) are statistically different. ${ }^{2, *}: p<0.05$; **: $p \leq 0.01$; ns: not significant; RMSE: root mean square error. 
The relative abundances of the genus Prevotella and Ruminococcus albus group were lower $(p<0.01)$ in the liquid from the fermenter compared to the liquid from rumen, while the preservation method did not show effects. On the contrary, the Fibrobacter succinogenes was higher $(p<0.01)$ in the liquid from the fermenter and its relative abundance in $\mathrm{W}$ and $\mathrm{R}$ liquids was higher $(p<0.01)$ than the others.

The results of the in vitro tests on the six feeds and the correlation coefficients calculated on the six feeds by using the sets of two inocula differing for origin (liquid from rumen versus liquid from fermenter) or preservation (W versus $R, W$ versus $C$ and $W$ versus FD liquids) are reported in Tables 3 and 4 , respectively. The in vitro tests used different inoculum and were performed in eight subsequent incubation sessions by each Lab. To correct any possible effect of the incubations session, a standard rumen fluid was included in each fermentation, which was used on the same substrate (corn silage) as the control. The data from the standard allowed the exclusion of any appreciable effect of the incubation session and the in vitro results from the different incubation sessions did not require corrections.

The NDFd data of the corn silage samples for the FD mode of preservation were removed from the analysis, having an abnormal fermentation due to technical problems.

The utilization of the liquid from the fermenter determined a significant NDFd reduction for three feeds (corn silage, wheat bran, and distillers) and the correlation analysis indicated a close relationship for NDFd between the liquid from rumen and diluted liquids from the fermenter $(\mathrm{r}=0.960, p \leq 0.01)$. Considering the preservation of the inoculum, the $\mathrm{W}$ and $\mathrm{R}$ liquids were not different for all the tested feeds and the correlation indicated a close correspondence $(\mathrm{r}=0.985, p \leq 0.01)$. The $\mathrm{C}$ and FD liquids depressed $(p \leq 0.01)$ the NDFd for two and three feeds, respectively. However, the correlation $\mathrm{W}$ versus $\mathrm{C}$ was high $(\mathrm{r}=0.905, p \leq 0.01)$, while the $\mathrm{W}$ versus FD was non-significant.

The RDP results indicated a good correspondence between fluid from the fermenter and liquid from the rumen liquids and the correlation between the liquid from rumen and the liquid from the fermenter data was high $(\mathrm{r}=0.837, p \leq 0.01)$. The $\mathrm{R}$ and $\mathrm{C}$ liquids gave similar $\mathrm{RDP}$ results to $\mathrm{W}$ liquid for all feeds and the regression $W$ versus $R$ showed a good correspondence of values $(r=0.892)$, while the $\mathrm{W}$ versus $\mathrm{C}$ was not significant. The RDP obtained with the FD liquid were quite variable, with the values for two feeds being higher than those obtained with $\mathrm{W}$, while for the soya, the opposite was true, and the correlation $\mathrm{W}$ versus FD was not significant.

Unlike NDFd and RDP, the gas production showed a significant interaction-inoculum $\times$ preservation ( $p \leq 0.01$ ) - for some feeds (corn silage, wheat bran, and distillers). However, the impact of the interaction in terms of the contribution to the mean square of the model was much lower than that of the main effects as well the level of significance $(p<0.05$ versus $p \leq 0.01)$. Therefore, it was decided to show the results and to discuss the main effects of the model. For all the feeds, the liquid from rumen gave higher gas production than the liquid from the fermenter ( $p \leq 0.01$ and, only for soya, $p<0.05)$.

Moreover, the preservation method had a statistical effect on the gas production ( $p \leq 0.01$ and, only for soya and barley, $p<0.05)$. In general, the gas production of $C$ was not statistically different from $\mathrm{W}$ and $\mathrm{R}$ liquids, except for wheat bran and barley where $\mathrm{C}$ gas production was not statistically different from W. The FD liquid generated the lowest yields of gas and all the ingredients differed significantly from those of the W liquid. All correlations of preserved liquids with W were statistically significant $(\mathrm{r}=0.797-0.921, p \leq 0.01)$. 
Table 3. In vitro degradability of NDF (NDFd), CP (RDP), and gas production (at $24 \mathrm{~h}$ of fermentation, GP) of six substrates using rumen inoculum differing for origin and for conservation method.

\begin{tabular}{|c|c|c|c|c|c|c|c|c|c|c|}
\hline \multirow{2}{*}{ Items } & \multicolumn{2}{|c|}{ Type of Inoculum (TI) } & \multicolumn{4}{|c|}{ Type of Conservation ${ }^{1}$ (TC) } & \multirow{2}{*}{$\mathrm{TI}^{2}$} & \multirow{2}{*}{$\mathrm{TC}^{2}$} & \multirow{2}{*}{$\mathrm{TI} \times \mathrm{TC}^{2}$} & \multirow{2}{*}{ RMSE $^{2}$} \\
\hline & From Rumen & From Fermenter & Warm (W) & Refrigerated (R) & Chilled (C) & Freeze-Dried (FD) & & & & \\
\hline \multicolumn{11}{|l|}{ NDFd (\%) } \\
\hline Corn silage & 37.5 & 30.1 & $39.0^{\mathrm{A}}$ & $40.0^{\mathrm{A}}$ & $22.5^{\mathrm{B}}$ & - & * & $* *$ & ns & 6.34 \\
\hline Wheat bran & 45.9 & 38.2 & $46.7^{\mathrm{A}}$ & $46.2^{\mathrm{A}}$ & $39.3^{\mathrm{B}}$ & $36.0^{\mathrm{B}}$ & $* *$ & ** & ns & 3.40 \\
\hline Meadow hay & 44.5 & 40.7 & $51.8^{\mathrm{A}}$ & $47.9^{\mathrm{A}, \mathrm{B}}$ & $39.0^{\mathrm{B}, \mathrm{C}}$ & $31.8^{\mathrm{C}}$ & ns & $* *$ & ns & 5.36 \\
\hline Distillers & 52.5 & 41.3 & 49.4 & 51.7 & 47.9 & 38.5 & * & ns & ns & 6.85 \\
\hline Soya meal, extr. & 81.4 & 78.5 & $92.2^{\mathrm{A}}$ & $93.7^{\mathrm{A}}$ & $85.5^{\mathrm{A}}$ & $48.5^{\mathrm{B}}$ & ns & $* *$ & ns & 6.26 \\
\hline Barley & 59.4 & 54.3 & 58.0 & 58.8 & 55.7 & 55.1 & ns & ns & ns & 5.39 \\
\hline \multicolumn{11}{|l|}{ RDP (\%) } \\
\hline Corn silage & 66.8 & 66.2 & $57.0^{\mathrm{b}}$ & $49.8^{\mathrm{b}}$ & $66.0^{\mathrm{b}}$ & $93.3^{\mathrm{a}}$ & ns & $*$ & ns & 15.21 \\
\hline Wheat bran & 59.9 & 61.9 & 58.1 & 58.9 & 60.4 & 66.2 & ns & ns & ns & 10.20 \\
\hline Meadow hay & 39.0 & 45.6 & $32.5^{b}$ & $27.8^{\mathrm{b}}$ & $44.3^{b}$ & $64.7^{\mathrm{a}}$ & ns & $*$ & ns & 11.35 \\
\hline Distillers & 33.8 & 34.5 & 34.8 & 37.5 & 33.8 & 30.6 & ns & ns & ns & 5.00 \\
\hline Soya meal, extr. & 45.1 & 53.4 & $52.8^{\mathrm{A}}$ & $56.8^{\mathrm{A}}$ & $47.8^{\mathrm{A}, \mathrm{B}}$ & $39.7^{\mathrm{B}}$ & $*$ & * & ns & 5.10 \\
\hline Barley & 59.0 & 57.4 & 51.8 & 49.7 & 60.4 & 71.0 & ns & ns & ns & 17.38 \\
\hline \multicolumn{11}{|l|}{$\mathrm{GP}(\mathrm{mL})$} \\
\hline Corn silage & 223 & 193 & $242^{\mathrm{A}}$ & $234^{\mathrm{A}}$ & $184^{\text {B }}$ & $172^{\mathrm{B}}$ & ** & $* *$ & ** & 26.13 \\
\hline Wheat bran & 183 & 146 & $176^{\mathrm{A}, \mathrm{B}}$ & $188^{\mathrm{A}}$ & $157^{\mathrm{B}, \mathrm{C}}$ & $136^{\mathrm{C}}$ & $* *$ & $* *$ & $* *$ & 18.40 \\
\hline Meadow hay & 162 & 119 & $177^{\mathrm{A}}$ & $198^{\mathrm{A}}$ & $124^{\mathrm{B}}$ & $64^{\mathrm{C}}$ & $* *$ & $* *$ & ns & 24.81 \\
\hline Distillers & 193 & 153 & $197^{\mathrm{A}}$ & $207^{\mathrm{A}}$ & $156^{\mathrm{B}}$ & $131^{\mathrm{B}}$ & $* *$ & $* *$ & $* *$ & 50.44 \\
\hline Soya meal, extr. & 178 & 134 & $176^{\mathrm{B}}$ & $213^{A}$ & $136^{\mathrm{C}}$ & $100^{\mathrm{D}}$ & * & * & ns & 23.31 \\
\hline Barley & 266 & 226 & $263^{\mathrm{A}, \mathrm{B}}$ & $264^{\mathrm{A}}$ & $231^{A, B}$ & $226^{\text {B }}$ & ** & * & ns & 27.85 \\
\hline
\end{tabular}

${ }^{1}$ Means of the type of conservation with different superscripts (A, B, C and a, b) are statistically different. ${ }^{2, *}: p<0.05 ;{ }^{* *}: p \leq 0.01$; ns: not significant; RMSE: root mean square error. 
Table 4. Pearson correlation coefficients ( $r$ ) of in vitro data obtained for the six feeds used as substrates in two fermentation run (12 observations) by using inocula differing for origin and for conservation.

\begin{tabular}{ccccccccc}
\hline & \multicolumn{7}{c}{ Type of Inoculum (TI) } & \multicolumn{5}{c}{ Type of Conservation (TC) } \\
\hline & Rumen vs. Fermenter & \multicolumn{1}{c}{ Warm vs. Refrigerated } & Warm vs. Chilled & Warm vs. Freeze-Dried \\
\hline & $\mathbf{r}$ & $\boldsymbol{p}^{\mathbf{1}}$ & $\mathbf{r}$ & $\boldsymbol{p}^{\mathbf{1}}$ & $\mathbf{r}$ & $\boldsymbol{p}^{\mathbf{1}}$ & $\mathbf{r}$ & $\boldsymbol{p}^{\mathbf{1}}$ \\
\hline $\mathrm{NDFd}^{2}$ & 0.960 & $* *$ & 0.985 & $* *$ & 0.905 & $* *$ & 0.554 & $\mathrm{~ns}$ \\
$\mathrm{RDP}^{3}$ & 0.837 & $* *$ & 0.892 & $* *$ & 0.345 & $\mathrm{~ns}$ & 0.431 & $\mathrm{~ns}$ \\
$\mathrm{GP}^{4}$ & 0.939 & $* *$ & 0.921 & $* *$ & 0.797 & $* *$ & 0.850 & $* *$ \\
\hline
\end{tabular}

${ }^{1}$ statistical significance of $\mathrm{r}:{ }^{* *}: p \leq 0.01$; ns: not significant. ${ }^{2}$ NDFd: NDF degradability; ${ }^{3}$ RDP: CP degradability;

${ }^{4} \mathrm{GP}$ : gas production (at $24 \mathrm{~h}$ of fermentation).

\section{Discussion}

\subsection{Type of Inoculum}

The present work used a rumen fluid collected from cows immediately after slaughter in controlled conditions (animals fed a known diet, not slaughtered in emergency, in good health status, transported from farms located near the slaughterhouse, rumen fluid sampled within 20 min of slaughter) as a reference in vivo rumen liquor. To our knowledge, there are no specific comparisons between rumen fluid collected via cannula, through the esophageal tube and at slaughtering. The authors reason that rumen fluid collected at slaughter in controlled conditions has a limited difference from that sampled by other methods. This is based on our previous work [24] where a close relationship between NDF degradability measured in vitro (average of rumen collected by different methods) and in situ was found. Our recent data [25] showed comparable values of in vitro NDF degradability using rumen fluids from slaughtered cows and from cows with rumen cannula fed similar diets. Moreover, the collection at slaughter is an accepted method of sampling rumen fluid for microbiota studies by the Rumen Microbial Genomics Network [26] and it is mentioned as an alternative to sampling via cannula [2].

A first aim of this study was to compare the fresh rumen inoculum with that obtained from a continuous culture system (RCF, see Figure 1). The data from the literature [4,5] showed that fermentation liquids from continuous cultures are less concentrated than rumen fluids collected directly from the rumen in terms of fermentation metabolites. This is confirmed also by data of this experiment, where a particularly low VFA concentration was found in the continuous fermenter liquids, being approximately $30 \%$ of the VFA concentration of rumen fluid. The concentration of VFAs measured in the rumen liquids were comparable to those found in the literature, while those of the RCF liquids were slightly lower than those obtained previously with the same in vitro system [14,27]. In addition, the ammonia reduction in the fermenter liquids was less marked than VFA, being approximately $60 \%$ of the ammonia in the rumen fluid. Moreover, a higher proportion of valeric and isovaleric acids was found in RCF liquids. These latter acids mainly originated from the metabolism of amino acids and this agrees with the relatively high ammonia concentration mentioned above.

The microbial population was represented in this study by only some bacterial strains and was affected by the type of inoculum. After the incubation period in the RCF, Prevotella genus and Ruminococcus albus group decreased the relative abundance, while Fibrobacter succinogenes increased, compared to the rumen liquids. F. succinogenes, both in the liquid from rumen and in the RCF liquids, was present at higher percentages than the R. albus group, as reported also from by Soto et al. [6,7] and by Koike et al. [28]. Our limited observations on the bacterial rumen microbiota confirm that the RCF in vitro environment shifts bacteria composition, because it depresses some strains and is favourable to others.

Despite the previously discussed differences between the two types of inoculum in terms of metabolites and microbiota concentration, the effects on the in vitro tests were less pronounced than expected, at least for NDF and crude protein degradability. On average, compared to the rumen fluid, 
the utilization of fermenter liquid inoculum determined a small reduction of NDFd $(-12 \%)$, while the degradability of protein was slightly increased $(+5 \%)$. Furthermore, the correspondence of NDFd data obtained on the six ingredients by the two inoculum was very close (r: $0.960, p \leq 0.01)$. On the contrary, gas production was depressed by $20 \%$ with the usage of RCF, but also in this case, there was a close correlation between the values obtained with the two types of inoculum ( $\mathrm{r}: 0.939, p \leq 0.01$ ). Therefore, despite the differences described above in metabolite and microbiota composition, the overall in vitro fermentability and the ranking of feeds in term of in vitro rumen fermentation do not seem to be greatly affected using the RCF fluid in comparison to rumen inoculum. This surprising result could be in part explained because the in vitro tests work at a high ratio of fermentation liquid to substrate (20, 50 and $180 \mathrm{~mL} / \mathrm{g}$ of DM substrate for RDP, GP and NDFd, respectively). In such conditions, there is an abundance of degrading capacity and it could be speculated that the RCF fermenting fluid is not so diluted to greatly reduce the fermentability measured by the in vitro tests, at least for the fiber and protein fractions.

\subsection{Method of Inoculum Preservation}

A second aim of this study was to compare the fresh rumen inocula with those preserved by refrigeration, chilling and freeze-drying (Figure 1). The rumen fluid maintained at $39^{\circ} \mathrm{C}$ for $5-6 \mathrm{~h}$ prior to incubation represented the reference rumen fluid because Robinson et al. [29] demonstrated that the storage in such conditions had no detrimental effects on in vitro NDF fermentation. The results of the present study show that rumen fluid refrigerated for 5-6 h had fermentative parameters very close to that of the fluid preserved at the animal body temperature. On the contrary, freezing at $-80{ }^{\circ} \mathrm{C}$ determined a high ammonia increment and the freeze-drying process caused pronounced variations in comparison with fresh rumen fluid because both acetic and propionic acids proportions were reduced, and the iso-butyric increased abnormally and the ammonia was severely reduced.

The NDFd values obtained from the fluid preserved by refrigeration were very similar to those attained from the inoculum maintained at $39^{\circ} \mathrm{C}$, as previously found by Robinson et al. [29]. A similar situation was found also for the RDP values, apart from the two forage samples. The same close relationship between refrigerated and fluid from rumen was also the case for gas production and this result confirms those found by Hervás et al. [30], who suggested that the preservation of rumen fluid for up to $6 \mathrm{~h}$ in crushed ice is a practical alternative to the use of freshly collected rumen fluid as inoculum for in vitro ruminal fermentation studies. Therefore, refrigerated inoculum can be a more practical system of storing rumen inoculum during transport from the site of collection to the laboratory of utilization within a 4 to $6 \mathrm{~h}$ period.

The possibility of storing the inoculum for long periods was evaluated in terms of chilling at $-80^{\circ} \mathrm{C}$ and by freeze-drying. The chilled inoculum determined a limited reduction of NDF degradation $(-14 \%)$ in comparison with the warm inoculum and there was a satisfactory relationship between feeds (r: 0.905).

Furthermore, the degradation of protein was, on average, not depressed and this agrees with the findings of Luchini et al. [31] who suggested that rumen inoculum preserved frozen might be used for in vitro rumen protein degradation experiments. However, the regression between feeds showed an insufficient degree of relation.

Finally, less gas was produced by the chilled inocula $(-20 \%)$ with a satisfactory relationship among feeds (r: 0.797). The protection of the microbiota from freezing damage can be obtained by adding organic chemicals with cryoprotectant properties but these compounds can interfere with the subsequent in vitro tests because they are fermentable substrates (e.g., glycerol, [12]) or can have toxic effects (e.g., dimethyl sulfoxide). A possible improvement of our chilling procedure $[9,12]$ could be to avoid freezing large amounts of inoculum and to divide it into small amounts (e.g., $30-50 \mathrm{~mL}$ ) because the high surface/volume accelerates the freezing.

The freeze-drying process produced the lowest fermentation activity and a very poor relation with fresh liquid among feeds, confirming similar findings obtained by Belanche et al. [9]. Several 
methodological factors can explain these poor results, such as the absence of cryoprotectants, the procedure of pellet preparation in terms of centrifugation intensity, and an improper process of rehydration. Systemic experimental work would be necessary to evaluate the role of specific conditions on the microbiota survival throughout whole process. Finally, it is worth noting that both preservation methods based on low temperatures, determined a drastic drop in the relative abundance of the Fibrobacter succinogenes, which plays a main role in fiber degradation. This variation could be associated with a depression of degradability and, consequently, with the low NDFD and GP values measured.

\section{Conclusions}

The results from the present trial indicate that fermentation liquid from rumen continuous fermenters can be used to generate inoculum for in vitro purposes. This result has relevant implications, not only in terms of artificially generating rumen fermenting fluids by RCF systems, but also from the perspective of the standardization of the fermentation liquids by adopting controlled fermentation conditions (e.g., substrate, dilution rate of saliva, fermentation, and $\mathrm{pH}$ ). Short-term refrigeration is confirmed to be a valuable storage system which has practical advantages in managing rumen fluid, particularly in the case of laboratories distant from collection sites. Finally, low fermentative capacity was found for chilled and, particularly, for freeze-dried liquids, and the procedures adopted to obtain such preserved inoculum probably require substantial improvements.

Author Contributions: Conceptualization, M.S., S.C., F.M., M.M. and F.T.; Data curation, M.S.; Formal analysis, M.C., C.F., F.F., F.M., C.S., S.S. and F.T.; Funding acquisition, M.S.; Project administration, M.S.; Writing-original draft, M.S.; Writing-review \& editing, S.C., F.M., M.M., S.S. and F.T.. All Authors participated in critical revision of the manuscript and all have approved the final draft submitted.

Funding: This work was financed by the Italian Ministry of Education, University and Research (PRIN 2015 2015FP39B9-LS9).

Conflicts of Interest: The authors declare no conflict of interest. The funders had no role in the design of the study; in the collection, analyses, or interpretation of data; in the writing of the manuscript, or in the decision to publish the results.

\section{References}

1. López, S. In vitro and in situ techniques for estimating digestibility. In Quantitative Aspects of Ruminant Digestion and Metabolism, 2nd ed.; CABI Publishing: Wallingford, UK, 2005; pp. 87-121.

2. Yáñez-Ruiz, D.R.; Bannink, A.; Dijkstra, J.; Kebreab, E.; Morgavi, D.P.; O’Kiely, P.; Reynolds, C.K.; Schwarm, A.; Shingfield, K.J.; Yu, Z.; et al. Design, implementation and interpretation of in vitro batch culture experiments to assess enteric methane mitigation in ruminants-A review. Anim. Feed Sci. Technol. 2016, 216, 1-18. [CrossRef]

3. Hristov, A.N.; Lee, C.; Hristova, R.; Huhtanen, P.; Firkins, J.L. A meta-analysis of variability in continuous-culture ruminal fermentation and digestibility data. J. Dairy Sci. 2012, 95, 5299-5307. [CrossRef] [PubMed]

4. Carro, M.D.; Ranilla, M.J.; Martin-García, A.I.; Molina-Alcaide, E. Comparison of microbial fermentation of high- and low-forage diets in Rusitec, single-flow continuous-culture fermenters and sheep rumen. Animal 2009, 3, 527-534. [CrossRef] [PubMed]

5. Muetzel, S.; Lawrence, P.; Hoffmann, E.M.; Becker, K. Evaluation of a stratified continuous rumen incubation system. Anim. Feed Sci. Technol. 2009, 151, 32-43. [CrossRef]

6. Soto, E.C.; Yánez-Ruiz, D.R.; Cantalapiedra-Hijar, G.; Vivas, A.; Molina-Alcaide, E. Changes in ruminal microbiota due to rumen content processing and incubation in single-flow continuous culture fermenters. Anim. Prod. Sci. 2012, 52, 813-822. [CrossRef]

7. Soto, E.C.; Molina-Alcaide, E.; Khelil, H.; Yáñez-Ruiz, D.R. Ruminal microbiota developing in different in vitro simulation systems inoculated with goats' rumen liquor. Anim. Feed Sci. Technol. 2013, 185, 9-18. [CrossRef] 
8. Martínez, M.E.; Ranilla, M.J.; Tejido, M.L.; Saro, C.; Carro, M.D. Comparison of fermentation of diets of variable composition and microbial populations in the rumen of sheep and Rusitec fermenters. II. Protozoa population and diversity of bacterial communities. J. Dairy Sci. 2010, 93, 3699-3712. [CrossRef]

9. Belanche, A.; Palma-Hidalgo, J.M.; Nejjam, I.; Serrano, R.; Jiménez, E.; Martín-García, I.; Yáñez-Ruiz, D.R. In vitro assessment of the factors that determine the activity of the rumen microbiota for further applications as inoculum. J. Sci. Food Agric. 2018, 99, 163-172. [CrossRef]

10. Chaudhry, A.S.; Mohamed, R.A.I. Fresh or frozen rumen contents from slaughtered cattle to estimate in vitro degradation of two contrasting feeds. Czech J. Anim. Sci. 2012, 57, 265-273. [CrossRef]

11. Denek, N.; Can, A.; Avci, M. Frozen rumen fluid as microbial inoculum in the two-stage in vitro digestibility assay of ruminant feeds. S. Afr. J. Anim. Sci. 2010, 40, 251-256. [CrossRef]

12. Prates, A.; de Oliveira, J.A.; Abecia, L.; Fondevila, M. Effects of preservation procedures of rumen inoculum on in vitro microbial diversity and fermentation. Anim. Feed Sci. Technol. 2010, 155, 186-193. [CrossRef]

13. Zeigler, L.D.; Schlegel, M.L.; Edwards, M.S. Development of a rumen fluid preservation technique and application to an in vitro dry matter digestibility assay. In Proceedings of the Fifth Conference on Zoo and Wildlife Nutrition, Chester, PA, USA, 5-8 October 2003; Ward, A., Brooks, M., Maslanka, M., Eds.; AZA Nutrition Advisory Group: Minneapolis, MN, USA, 2003.

14. Mason, F.; Zanfi, C.; Spanghero, M. Testing a stratified continuous rumen fermenter system. Anim. Feed Sci. Technol. 2015, 201, 104-109. [CrossRef]

15. Luchini, N.D.; Broderick, G.A.; Combs, D.K. Preservation of ruminal microorganisms for in vitro determination of ruminal protein degradation. J. Anim. Sci. 1996, 74, 1134-1143. [CrossRef]

16. Slyter, L.L.; Bryant, M.P.; Wolin, M.J. Effect of $\mathrm{pH}$ on population and fermentation in a continuously cultured rumen ecosystem. J. Appl. Microbiol. 1966, 14, 573-578.

17. Menke, K.H.; Steingass, H. Estimation of the energetic feed value obtained from chemical analysis and gas production using rumen fluid. Anim. Res. Dev. 1988, 28, 7-55.

18. Van Soest, P.J.; Robertson, J.B.; Lewis, B.A. Methods for dietary fiber, neutral detergent fiber, and nonstarch polysaccharides in relation to animal nutrition. J. Dairy Sci. 1991, 74, 3583-3597. [CrossRef]

19. Ross, D.A.; Gutierrez-Botero, M.; van Amburgh, M.E. Development of an in-vitro intestinal digestibility assay for ruminant feeds. In Proceedings of the Cornell Nutrition Conference, Syracuse, NY, USA, 22-24 October 2013; pp. 190-202.

20. Tagliapietra, F.; Cattani, M.; Bailoni, L.; Schiavon, S. In vitro rumen fermentation: Effect of headspace pressure on the gas production kinetics of cornmeal and meadow hay. Anim. Feed. Sci. Technol. 2010, 158, 197-201. [CrossRef]

21. AOAC International. Official Methods of Analysis of AOAC International, 17th ed.; AOAC International: Gaithersburg, MD, USA, 2000.

22. Martillotti, F.; Puppo, S. Liquid chromatographic determination of organic acids in silages and rumen fluids. Ann. dell'Istituto Sper. Zootec. 1985, 18, 1-10.

23. Kong, Y.; Teather, R.; Forster, R. Composition, spatial distribution, and diversity of the bacterial communities in the rumen of cows fed different forages. FEMS Microbiol. Ecol. 2010, 74, 612-622. [CrossRef]

24. Spanghero, M.; Berzaghi, P.; Fortina, R.; Masoero, F.; Rapetti, L.; Zanfi, C.; Tassone, S.; Gallo, A.; Colombini, S.; Ferlito, J.C. Technical note: Precision and accuracy of in vitro digestion of neutral detergent fiber and predicted net energy of lactation content of fibrous feeds. J. Dairy Sci. 2010, 93, 4855-4859. [CrossRef]

25. Spanghero, M. (Dipartimento di Scienze Agroalimentari, Ambientali e Animali, University of Udine, Udine, Italy). Unpublished work. 2019.

26. Rumen Microbial Genomics Network. A Report in Support of the Rumen Microbial Genomics (RMG) Network Describing Standard Guidelines and Protocols for Data Acquisition, Analysis and Storage. Available online: http://www.rmgnetwork.org/user/file/37/RMG\%20Network\%20Report\%20standard\%20guidelines. pdf (accessed on 14 October 2019).

27. Spanghero, M.; Mason, F.; Zanfi, C.; Nikulina, A. Effect of diets differing in protein concentration (low vs medium) and nitrogen source (urea vs soybean meal) on in vitro rumen fermentation and on performance of finishing Italian Simmental bulls. Livest. Sci. 2017, 196, 14-21. [CrossRef]

28. Koike, S.; Pan, J.; Kobayashi, Y.; Tanaka, K. Kinetics of in sacco fiber-attachment of representative ruminal cellulolytic bacteria monitored by competitive PCR. J. Dairy Sci. 2003, 86, 1429-1435. [CrossRef] 
29. Robinson, P.H.; Campbell Mathews, M.; Fadel, J.G. Influence of storage time and temperature on in vitro digestion of neutral detergent fibre at $48 \mathrm{~h}$, and comparison to $48 \mathrm{~h}$ in sacco neutral detergent fibre digestion. Anim. Feed Sci. Technol. 1999, 80, 257-266. [CrossRef]

30. Hervás, G.; Frutos, P.; Javier Giráldez, F.; Mora, M.J.; Fernández, B.; Mantecón, A.R. Effect of preservation on fermentative activity of rumen fluid inoculum for in vitro gas production techniques. Anim. Feed Sci. Technol. 2005, 123, 107-118. [CrossRef]

31. Luchini, N.D.; Broderick, G.A.; Combs, D.K. In vitro determination of ruminal protein degradation using freeze-stored ruminal microorganisms. J. Anim. Sci. 1996, 74, 2488-2499. [CrossRef] [PubMed]

(C) 2019 by the authors. Licensee MDPI, Basel, Switzerland. This article is an open access article distributed under the terms and conditions of the Creative Commons Attribution (CC BY) license (http://creativecommons.org/licenses/by/4.0/). 